\title{
Ainda a medicina baseada em evidências
}

Mônica Teixeira

$\mathrm{O}$ artigo que Observando a Medicina publica nesta edição dá continuidade à colaboração da Revista Latinoamericana de Psicopatologia Fundamental com The Lancet, a importante revista médica inglesa, que publicou o texto de Allan Sniderman na seção Viewpoint (Ponto de vista). Seu autor é cardiologista, professor da McGill University, do Quebec, no Canadá. Em Ensaios clínicos, conferências de consenso e prática clínica, Sniderman aponta limites raramente destacados da autodenominada Medicina Científica, que pretende determinar os padrões de tratamento a serem aplicados pelos clínicos a seus pacientes. Ao avaliar como se dá o estabelecimento de diretrizes clínicas em grandes reuniões de especialistas chamadas “conferências de consenso", com base na interpretação de dados obtidos através de ensaios clínicos, Sniderman ressalta problemas fundamentais do procedimento, como, por exemplo, ser apresentado por seus adeptos como "impessoal”, ou "objetivo". O médico canadense também observa como, nas conferências de "consenso", o consenso é obtido preliminarmente às reuniões dos especialistas, uma vez que a divergência é banida preventivamente por meio 
do controle da filiação intelectual dos especialistas escolhidos. Sniderman advoga que os médicos, em vez de se deixarem guiar pelas diretrizes elaboradas pelas conferências de consenso, a que são atribuídas as virtudes da perfeição, prefiram, antes, pensar pela própria cabeça.

O artigo foi publicado em julho de 1999. O passar dos anos não lhe tirou a atualidade ou diminuiu a clareza. $\mathrm{O}$ autor permanece um ativo praticante da medicina: em junho de 2003, publicou na mesma The Lancet um artigo em que põe em questão o uso da medida de níveis de colesterol como indicador de risco para ataques cardíacos - tema que o leitor encontrará, como ponto de argumentação, no artigo a seguir. 